\title{
Research Programmes that Address Societal Challenges - Aligning Policy, Implementation, and Expected Impact
}

\author{
Irene Ek \\ Senior Analyst, Irene.Ek@tillvaxtanalys.se \\ Swedish Agency for Growth Policy Analysis, Torsgatan 11, Stockholm, Sweden
}

\begin{abstract}
7 his article explores research programs that address societal challenges. In recent years, the rationale for innovation policy has been extended to include support instruments more explicitly designed to address societal challenges. While there are broad agreements that in this rationale research and innovation support can not only stimulate growth and economic activity, but they can also actively be directed towards meeting societal challenges.

However, exploring how societal challenge policy goals can be translated into something that the support instruments can influence, is not yet the focus of challenge-driven innovation policy and a topic that seems to be neglected in the research literature. This article develops a framework for a cross country analysis of how policy, programs, and impact align and highlight what can be learned from selected societal challenge programs.
\end{abstract}

\section{Keywords:}

societal challenges; policy alignment; innovation policy; research programmes; programme design; impact; evaluation
Citation: Ek I. (2018) Research Programmes that Address Societal Challenges - Aligning Policy, Implementation, and Expected Impact. Foresight and STI Governance, vol. 12, no 3, pp. 13-19. DOI: 10.17323/2500-2597.2018.3.13.19 
$\mathrm{T}$ The debate over research and innovation policy that address societal challenges has received increased attention over recent years [Edler, Boon, 2018; Foray et al., 2012; George et al., 2016; Kallerud et al., 2013; Kuhlmann, Rip, 2016; Mazzucato, 2015, 2018; Weber, Stephanie, 2014]. Researchers and policy makers alike are increasingly focusing on the difficulties stemming from the complexity of policy. A growing number of countries turn their attention to societal challenges like climate change, health, and sustainable society [DFiR, 2017; Finnish Government, 2014; Swedish Government, 2016; UK Government, 2015]. Scholars have recognized that the instruments that implement policies directed at societal challenges need to encompass a diverse set of actors and address multiple objectives [Edler, Boon, 2018; Foray et al., 2012; Kuhlmann, Rip, 2016]. It is argued that this complexity calls for a systemic approach.

It is not only individual countries that turn their focus toward societal challenges. Looking at the EU's plans for the new research program Horizon Europe for 2021-2027, it was put forward that the research supported by the program would tackle the major global challenges of our time and contribute to achieving the Sustainable Development Goals [Mazzucato, 2018]. The literature suggests that the role of the state in innovation policy is changing. It is becoming increasingly important for both researchers and policy makers to explore how to use research and innovation to solve the pressing global challenges of our time.

The ability of innovation to drive economic growth has long been recognized [Bloom et al., 2013; OECD, 2015]. Less recognized is the view that innovation also has a direction [Mazzucato, 2018]. By harnessing the directionality of innovation, it is suggested that it is also possible to harness the power of research and innovation in order to achieve wider social and policy aims as well as economic goals. Rather than supporting traditional research and innovation programs that deliver incremental results, the state is increasingly seen as an actor that can shape the directionality of innovation, i.e., create the conditions for systemic transformation [Geels et al., 2017]. This shift is most clearly expressed in "challenge"-oriented policies that seek to define areas of societal concern and tackle defined societal challenges.

The present article analyzes the experience of working with national research programs in selected countries. These case studies provide empirical descriptions of existing practices, with conclusions about important factors to consider in the design and implementation of such national research programs.

Case studies of the following five programs have been carried out:

- Denmark - Grand Solutions

- United Kingdom - Prime Minister's Challenge on Dementia

- Canada - NRC-CNRC, Arctic Program

- Finland - Strategic Research Council (SRC), focus on Climate Neutral Finland

- EU - JPI, focus on climate change

In Sweden, research programs that address societal challenges are a relatively new phenomenon [Swedish Government, 2016]. They differ from more "traditional" programs in the following ways [FORMAS, 2017]. First, they are longer as they extend beyond the time span of two research bills. Second, they are more ambitious in scope. Third, they aim to achieve a strategic overall coordination of research funding and other activities in Sweden, and are expected to create synergies between different actors. Fourth, rather than focusing on creating a project portfolio in line with program objectives (as in the case of "traditional" research programs), they also aim to function as a platform for new and ongoing research and to be a link to international programs and EU Joint Programming Initiatives. Finally, they aim to contribute to an increased impact in society in terms of development, knowledge building, evidence-based policies and management, and ultimately to contribute to national policy goals. The need for an international scanning report was articulated by the Swedish Research Council for Sustainable Development and the lessons learned have been presented to the Swedish Research Councils [Tillväxtanalys, 2017].

\section{Method}

Several properties make the study of research and innovation programs that address societal challenges particularly demanding from a methodological perspective. First, these are complex programs embedded in different national contexts. The need to gather and conduct a cross country comparative analysis is recognized in the literature. Intensified globalization requires public administration research to embrace a comparative perspective [Fitzpatrick et al., 2011]. In addition, several countries face the same challenges increasing the need for coordination. Second, in some sense it is an ex-ante exploration as some of the selected programs are still ongoing. While the budget and governance structures are fixed, the program design can, to some extent, still be developed and undergo changes, thus it remains somewhat flexible.

To mitigate these constraints, this paper presents five qualitative case studies about research and innovation programs that address societal challenges in selected countries. These case studies allow for an in-depth study of emerging programs that address societal challenges. Case studies allow the researcher to deal with a variety of material such as documents and interviews [Yin, 2003]. In this article, data has been collected and analyzed from a diverse set of sources including program documents and 15 semi-structured interviews with program experts from each respective country. 
The semi-structured interviews were focused on program design, implementation, and covered the following questions:

- Can you describe the process for program design and setting the research agenda? Which actors participated? What helped that happen?

- Can you describe the support instruments that were used?

- Can you describe the governance structure of the program? Does the governance structure allow for flexibility and if so how?

- Can you describe how collaboration takes place? How does it happen?

- Is the program evaluated, if so, what were the results?

\section{Theoretical Framework}

This article attempts to address the problem of developing and implementing policies that seek to alleviate the pressing global challenges of our time. A framework was introduced that sets out the elements and illustrates the flow from policy goal to the instrument deployed, and finally to the impacts that the selected instrument can deliver. In other words, it shows how the nested relations between policy, instrument, and impact align. The framework expands upon existing literature as it highlights a new form of policy coherence that is compatible with a more sophisticated, multi-actor, and dynamic understanding of the processes by which policies that address societal challenges are implemented and can deliver societal impact.

Policy makers and researchers alike are increasingly focusing upon challenges that demand a complex policy approach. This shift in emphasis is exemplified by the adoption of the term "policy mix", which implies a focus on coherence, i.e., the interactions and interdependencies between different support instruments as they affect the extent to which policy goals are realized [Flanagan et al., 2011]. In addition, the literature emphasizes the fact that support instruments are not intended to (and cannot) influence the ultimate policy objectives (e.g., system transformation) in an immediate sense because these instruments can only influence the innovation and industrial development processes. This implies that the ultimate policy objectives must be "translated" into concrete problems that can be influenced directly by support instruments [Borrás, Edquist, 2013].

Thus far, there have been a number of more theoretical studies that address societal challenges. This article expands upon this previous literature [Cejudo, Michel, 2017; Edler, Boon, 2018; Koff, 2017; Mazzucato, 2018] and it introduces a new framework that is used to analyze empirical examples from a number of programs that address societal challenges. The research question is, "How coherent are the policies for the implementation of these transformative objectives that characterize societal challenges?" Any progress in addressing complex problems such as societal challenges requires empirically clarifying these policy initiatives and showing their implications for policy design and implementation.

This article explores the problem of developing and implementing policies that address societal challenges. It offers new recommendations regarding new support instruments by introducing the idea of describing the choice and formulation of the support instruments that make up the implementation of societal challenges. There may be serious consequences, if the choices of support instrument for such complex programs as societal challenges are not specifically addressed.

To this end, Figure 1 proposes a new framework that set out the elements necessary to illustrate the flow from the policies that address societal challenges, to the instruments deployed, and finally to the impacts that the selected instruments can have. In other words, how the nested relationships between policy, instrument, and impact align. This new framework is designed to highlight a new type of policy coherence that is compatible with a more sophisticated, multi-actor, and dynamic understanding of the processes from which policy that aims for system transformation emerges, how it is implemented, and what impact can be expected.

The framework presented here is used to conduct a coherence analysis of how the nested relationships between policy, support instrument, and impact align. High coherence indicates that the political objective can be implemented. Low coherence indicates that that the selected support instruments cannot fully implement the policy objectives.

The present results indicate that the political objectives and the support instruments do not fully align. The policy objective to address societal challenges has been followed by the launch of research programs. Following the flow from the policy objectives, the choice of support instruments was fairly traditional and could not fully implement the transformation necessary to address the societal challenge.

There is a gap in the literature when it comes to theories that are used to understand the implementation of policies that address societal challenges and require system transformation. Societal challenges are an area of policy-making that is characterized by the need for coordination between policy domains [Trein, 2017]. OECD innovation strategy highlights the need for vertical as well as horizontal governance [OECD, 2015], which implies that the public authorities in charge belong to various levels of authority and policy competences. Effective policies for system transformation might need to be joined up, across 


\begin{tabular}{|c|c|c|}
\hline $\begin{array}{l}\text { Rationale for policy } \\
\text { expanded to tackle } \\
\text { societal challenges }\end{array}$ & $\begin{array}{l}\text { Requires multi-stakeholder } \\
\text { design and implementation }\end{array}$ & $\begin{array}{l}\text { Solve an important societal problem with the } \\
\text { likelihood of global impact through widespread } \\
\text { implementation } \\
\text { System transformation }\end{array}$ \\
\hline Policy goals & & Expected impact \\
\hline
\end{tabular}

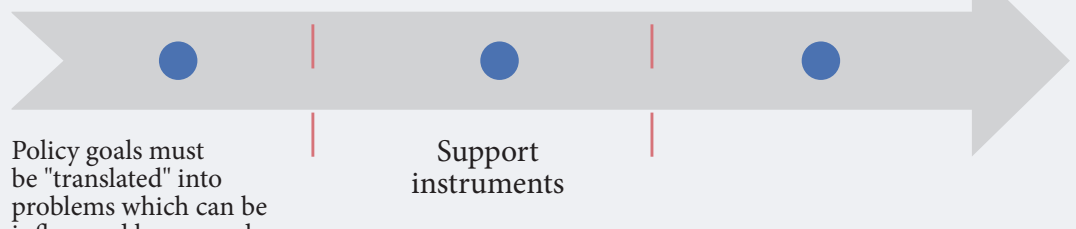

problems which can be

programs

Source: compiled by the author.

Alignment/coherence

a broad set of policy areas, including research policy, industrial policy, environmental policy, and public sector policy. This increases the number of actors and agendas that need to be coordinated in order to achieve coherent policies.

\section{Case Findings}

The case description below is a summary of an international review of research programs that focus on societal challenges performed by the Swedish Agency for Growth Policy Analysis [Tillväxtanalys, 2017]. The five case studies show certain differences and some similarities. This section summarizes these findings and explores practices for such programs.

The cases present some common features. They all address societal challenges as this was part of the selection criteria. Still, there are differences in how specific or generic these programs are. Some address more universally agreed upon societal challenge topics (e.g., climate change) and some are more targeted or local in scope, such as the dementia challenge in the UK or the challenges of living and conducting business in the Arctic in Canada.

Some of the case studies, such as the Danish Grand Solutions and A Climate-Neutral and ResourceScarce Finland, broadly define the challenge or challenges to be addressed, but leave it to the applicant to define how and what part of the challenge to tackle. The UK Dementia challenge and Canada Arctic Program are much more specific in the issues they address.

The scope of the programs, in terms of budget and time limit, varies. The Danish Grand Solutions program funds projects that have a life span of three to five years; the UK and Finnish cases run from 2015 to 2020; the Canadian Arctic Program case is an eight-year program, whereas the Climate JPI has no fixed end date. The annual budgets are difficult to compare, but those of the Danish and UK cases are larger than the others.

All the case study programs involve a higher degree of stakeholder consultation than what is normally seen in research and innovation programs, although the nature of the interaction of different types of stakeholders varies between the programs. They are all explicitly "top down", in the sense that government sets the policy objectives to be implemented in the program. However, there is then variation in how the policy objective is translated into a specific research program. The UK Dementia challenge has a detailed program design that considers the correlation between individual activities and therefore involves the development of infrastructure as well as research. Canada's Arctic Program is designed within the NRC and presumably is in line with the NRC's larger research program and its implementation.

The other three cases do not involve mutually consistent, programmed activities that together build towards a predetermined goal. Thus, the Danish Grand Solutions are selected from the bottom-up within the government's thematic priorities. Similarly, Finland's Strategic Research Programmes select the proposals that meet the thematic and quality criteria but do not have a collective architecture. Finally, the JPIs fund bottom-up research within the thematic priorities agreed upon among the participating states. The five cases show different mechanisms for providing input in the decision-making process. For example, decisions on funding allocations for challenge areas in Denmark are taken up by policy makers (topdown) but these decisions refer to a non-binding "catalogue" of priority areas developed in consultation 
Table 1. Similarities and Differences among National Research Programs

\begin{tabular}{|l|l|l|l|l|l|}
\hline \multicolumn{1}{|c|}{ Features } & \multicolumn{1}{|c|}{ UK } & \multicolumn{1}{c|}{ Denmark } & \multicolumn{1}{c|}{ Finland } & \multicolumn{1}{c|}{ Canada } & \multicolumn{1}{c|}{ Japan } \\
\hline Budget & $>£ 300 \mathrm{mln}$ & $600 \mathrm{~m}$ DKK/year & $€ 17 \mathrm{mln}$ & \$ CAN 86 mln & Not defined \\
\hline Time & $2015-2020$ & 3-5 years & $2015-2020$ & 8 years & Not defined \\
\hline Focus & Dementia & $\begin{array}{l}\text { Several, i.e., energy } \\
\text { and health }\end{array}$ & Climate change & $\begin{array}{l}\text { Business development } \\
\text { in an Arctic climate }\end{array}$ & Climate change \\
\hline Governance & $\begin{array}{l}\text { Partnership both top- } \\
\text { down and bottom-up }\end{array}$ & $\begin{array}{l}\text { Theme: mostly top- } \\
\text { down } \\
\text { Choice of program: } \\
\text { bottom-up }\end{array}$ & $\begin{array}{l}\text { Formulation: top-down } \\
\text { Selection: bottom-up }\end{array}$ & $\begin{array}{l}\text { Top-down selection } \\
\text { of four areas, bottom- } \\
\text { up selection of } \\
\text { technologies }\end{array}$ & Bottom-up \\
\hline Participants & $\begin{array}{l}\text { Public and private sector, } \\
\text { health sector, NGOs, } \\
\text { researchers, patients, } \\
\text { care-givers, public }\end{array}$ & $\begin{array}{l}\text { Public and private } \\
\text { sector, researchers } \\
\text { and users }\end{array}$ & $\begin{array}{l}\text { University, institutes, } \\
\text { companies and } \\
\text { some international } \\
\text { participants }\end{array}$ & $\begin{array}{l}\text { Public and private } \\
\text { sector }\end{array}$ & $\begin{array}{l}17 \text { member } \\
\text { countries }\end{array}$ \\
\hline Source: compiled by the author based on [Tillväxtanalys, 2017]. & & \\
\hline
\end{tabular}

with the sector. A similar catalogue is used in Finland, which is prepared by the research council. This means that although this process is formally top-down from the policy-makers, it still permits input from stakeholders. How these themes are expressed in the actual proposals and partnerships is usually decided upon through a bottom-up process in which the applicants describe the issues to be tackled and chose them according to certain pre-set criteria. These criteria can be tilted more towards innovation (as in the case of the Danish Grand Solutions, in which value creation is a decisive factor) or more towards research (as in A Climate-Neutral and Resource-Scarce Finland, in which certain guiding principles and research issues are decisive).

It seems reasonable to suppose that the UK Dementia challenge and Canada's Arctic Program will make progress towards the practical implementation of goals while the other three cases are more likely to produce knowledge that may or may not turn out to be useful in setting agendas and developing policy.

The style of governance follows the same pattern, with the UK Dementia challenge and presumably the Canadian Arctic Program, being closely monitored and governed. A rather strong vertical coordination emerges in the Danish and Finnish cases, in which central government plays an active role in defining priorities and budgets. The UK Dementia case is more about horizontal coordination, with collaboration between sector agencies and ministries. The Board of the UK Dementia Programme comprises senior leaders from many partner organizations involved in the challenge and is chaired by the Parliamentary Under Secretary of State. Major individual initiatives under the program have their own governance structures. In the case of the Danish Grand Solutions, IFD is led by a Board of Directors comprising nine politically-appointed members with research and industry expertise. The Fund reports to the Ministry for Education and Research but functions at arm's length from the government. Unlike the Fund's other schemes, all decisions concerning investments in Grand Solutions are taken directly by the Board. The other three cases follow a more traditional research council model of defining thematic priorities, selecting projects, and then allowing nature to take its course.

The Joint Programming Initiative was evaluated in 2016 and is the only one of the cases studied that has been formally evaluated thus far. Most of the other programs have been scheduled for such analyses in the near future. An internal Progress Review Group continually monitors the key performance indicators of the UK Dementia Programme, which in this respect stands out as more detailed and, possibly, more ambitious than the other programs. The program's approach of discussing beforehand what must be done to achieve the desired outcomes and impact in the short, medium, and long term, and what success will look like at each stage, could be a lessons learned for challenge-led research programs elsewhere.

\section{Results}

All the cases studied are top-down in the sense that they stem from a political decision. It seems clear that the aim to align the program with national priorities is a common feature. The inclusion of a broad spectrum of stakeholders in designing the programs is common and, in turn, favors networking with new stakeholders and decision-makers.

Public-private partnerships (PPPs) such as the UK Dementia Challenge involve a transfer of programming activity and research agenda setting from the funding organization to the partnership. This may create a principal-agent problem, providing an incentive to the partnership to follow its own narrower goals rather than those of the funder. Therefore, this type of program may require close monitoring and supervision by the funder, which is to some extent reflected in the governance structure of the Dementia challenge, with multiple checks and balances.

A program that draws on a national strength is more likely to be perceived by the respondents as being successful. This is highlighted in all of the case studies. 
Although the overarching initiative, and possibly even its objectives or goals, are set from the beginning, deciding on the actual program design and content through a flexible, interactive, and inclusive process would seem to increase the likelihood of a successful program.

All the case study programs involve a higher degree of stakeholder consultation than is normally seen in research and innovation programs. Early dialogue with stakeholders about priorities seems to favor inclusion and commitment. The respondents all describe a dialogue that strives to include all relevant partners from the outset through planning to delivery.

\section{Concluding Remarks}

The traditional focus on the research and innovation processes has served us well in the past, when a central policy aim was to promote excellent research and economic growth. Now, policymakers are more concerned about complex societal challenges. These concerns are transforming much of research and innovation policy.

Policymakers have already begun to take a more systemic view than before on innovation, growth, and development. They are now trying to put policies into place that help address the societal challenges. This article provides further empirical nuances that support Arnold et al.s [Arnold et al. 2018] view that these policy initiatives involves greater coordination across different parts of society including stakeholders well outside of what we have historically regarded as the research and innovation community, creating larger-scale and longer-term programs that span more actors than before - both horizontally across different sectors of society and also vertically, with activities taking place at international, national, and regional levels. As policy interventions become larger and more complicated, involving greater numbers of actors, coordination becomes increasingly important. The cases highlight a move towards what Edler and Boon [Edler, Boon, 2018] describe as a demand-driven process for identifying the research priorities and program design.

This article also provides a coherence analysis of how the nested relationships between policy, instrument, and impact align. High coherence indicates that the political objective of addressing societal challenges can be implemented. Low coherence indicates that that the selected instrument cannot fully implement the changes needed to address societal challenges. The present results indicate that the political objectives and the selected support instruments do not fully align. Following the flow from the policy objectives to the implementation, it becomes clear that some parts of the policy to address societal challenges are still waiting to be implemented. Although the programs studied here have a somewhat new dimension, a large part of their design is still more traditional. Delivering the system transformation required to address societal challenges with programs that remain traditional is problematic. System transformations are important as many of the societal challenges seem likely to require them. Still the literature provides few examples of how these new types of complex programs can be designed, implemented, and evaluated.

The text in this article is the writer's own view and not that of the Swedish Agency for Growth Policy Analysis.

\section{References}

Arnold E., Åström T., Glass C., de Scalzi, M. (2018) How should we evaluate complex innovation programmes and sustainability transitions? Stockholm: Technopolis Group.

Bloom N., Schankerman M., van Reenen J. (2013) Identifying Technology Spillovers and Product Market Rivalry. Econometrica, vol. 81, no 4, pp. 1347-1393. DOI: 10.3982/ECTA9466.

Borrás S., Edquist C. (2013) The choice of innovation policy instruments. Technological Forecasting and Social Change, vol. 80, pp. 1513-1522. Available at: https://doi.org/10.1016/j.techfore.2013.03.002, accessed 15.02.2017.

Cejudo G.M., Michel C.L. (2017) Addressing fragmented government action: Coordination, coherence, and integration. Policy Sciences, vol. 50, no 4, pp. 745-767. DOI:10.1007/s11077-017-9281-5.

DFiR (2017) Danish Research Bill. RESEARCH2025, Copenhagen: Danish Council for Research and Innovation Policy (DfiR).

Edler J., Boon W.P. (2018) The next generation of innovation policy: Directionality and the role of demand-oriented instruments' - Introduction to the special section. Science and Public Policy (forthcoming). DOI: 10.1093/scipol/ scy026.

Finnish Government (2014) Government Proposal for a New Climate Change Act to Parliament (HE 82/2014, 5 June 2014), Helsinki: Finnish Government.

Fitzpatrick J., Goggin M., Heikkila T., Klingner D., Machado J., Martell C. (2011) A New Look at Comparative Public Administration: Trends in Research and an Agenda for the Future. Public Administration Review, vol. 71, no 6, pp. 821-830. 
Flanagan K., Uyarra E., Laranja M. (2011) Reconceptualising the 'policy mix' for innovation. Research Policy, vol. 40, no 5, pp. 702-713. Available at: https://doi.org/10.1016/j.respol.2011.02.005, accessed 27.11.2017.

Foray D., Mowery D.C., Nelson R.R. (2012) Public R\&D and social challenges: What lessons from mission R\&D programs? Research Policy, vol. 41, no 10, pp. 1697-1702. Available at: http://dx.doi.org/10.1016/j. respol.2012.07.011, accessed 14.03.2018.

Geels F.W., Sovacool B.K., Schwanen T., Sorrell S. (2017) Sociotechnical transitions for deep decarbonization. Science, no 357(6357), pp. 1242-1244. DOI:10.1126/science.aao3760.

George G., Howard-Grenville J., Joshi A., Tihanyi L. (2016) Understanding and Tackling Societal Grand Challenges through Management Research. Academy of Management Journal, vol. 59, no 6, pp. 1880-1895. DOI: 10.5465/ amj.2016.4007.

Kallerud E., Amanatidou E., Upham P., Nieminen M., Klitkou A., Sutherland Olsen D., Toivanen M.L., Oksanen J., Scordato L. (2013) Dimensions of research and innovation policies to address grand and global challenges (Working Paper 13/2013), Oslo: NIFU.

Koff H. (2017) Diaspora Philanthropy in the Context of Policy Coherence for Development: Implications for the post2015 Sustainable Development Agenda. International Migration, vol. 55, no 1, pp. 5-19. DOI: 10.1111/imig.12277.

Kuhlmann S., Rip A. (2016) The challenge of addressing Grand Challenges. A think piece on how innovation can be driven towards the "Grand Challenges" as defined under the prospective European Union Framework Programme Horizon 2020, Brussels: European Commission.

Mazzucato M. (2015) A mission-oriented apporach to building the entrepreneurial state (Report commissioned by the UK Government), London: UK Government.

Mazzucato M. (2018) Mission-oriented Research \& Innovation in the European Union. A Problem-solving Approach to Fuel Innovation-led Growth, Brussels: European Commission.

OECD (2015) OECD Innovation Strategy 2015. An Agenda for Policy Action, Paris: OECD.

FORMAS (2017) Report to the Swedish Government on how the work with the natonal programmes evolves, Stockholm: Swedish Research Council for Sustainable Development (FORMAS).

Swedish Government (2016) Swedish Research Bill. Collaborating for knowledge - for society's challenges and strengthened competitiveness, Stockholm: Swedish Government.

Tillväxtanalys (2017) International scanning of research programmes that focus on societal challenges (vol. PM 2017:18), Stockholm: The Swedish Agency for Growth Policy Analysis (Tillväxtanalys).

Trein P. (2017) Coevolution of policy sectors: A comparative analysis of healthcare and public health. Public Administration, vol. 95, no 3, pp. 744-758. DOI: 10.1111/padm.12323.

UK Government (2015) Prime Minister's Challenge on Dementia 2020, London: UK Government.

Weber M., Stephanie D. (2014) Exploring transformative research and innovation futures and their embedding in the ERA. Paper presented at the 5th concerence on the Future-Oriented Technology Analysis (FTA) 2014 "Engage today to shape tomorrow", Brussels, November 2014.

Yin R.K. (2003) Case study research: Design and methods, Thousand Oaks: Sage Publications. 